Vantage: Journal of Thematic Analysis

ISSN: 2582-7391

A Multidisciplinary Publication of Centre for Research, Maitreyi College, University of Delhi

October 2020, Volume 1, Issue 2

Invited Article

\title{
COVID-19 in India; A brief review of preventive measures and the path ahead
}

\author{
Pranav Ish $^{1}$ and, Neeraj Nischal ${ }^{2 *}$ \\ 1- Assistant Professor of Pulmonary Medicine, Safdarjung Hospital, New Delhi \\ 2- Associate Professor of Medicine, AIIMS, New Delhi \\ *Correspondence: neerajnischal@gmail.com
}

\begin{abstract}
COVID-19 has spread in pandemic proportions. With the continued rise in cases in India, there is an urgent need to strictly follow all preventive measures possible. In the wait for an effective vaccine and cure; physical distancing, masks, sanitisers and exposure prevention are the best weapons available in the current times and cannot be overemphasized.
\end{abstract}

Keywords: COVID-19, Prevention, Masks

\section{INTRODUCTION}

Coronaviruses are a large group of viruses that can cause illness in humans and animals. Occasionally, animal coronaviruses can evolve, mutate and infect people, and as such has been seen with Middle East respiratory syndrome (MERS) and Severe acute respiratory syndrome (SARS) in the previous years. The outbreak of Novel coronavirus disease (COVID-19) was initially noticed in China in December, 2019 and eventually spread to over 200 countries worldwide. The World Health Organisation (WHO) has declared this outbreak as a "Public Health Emergency of International Concern" (PHEIC) on $30^{\text {th }}$ January 2020 and as a pandemic on 11th March, 2020. India has recorded over 4.7 million cases by September 2020 with a continued rise (Corona Meter, 2020). There are multiple drugs being used for the treatment with emerging evidence (Table 1). However, except for steroids administered in severe and oxygen requiring patients, no drug has shown a mortality benefit yet (RECOVERY 
Collaborative Group, 2020). There are multiple vaccine trials going on in the world with 3 vaccines in phase 2 and 3 trials in India (Table 2). In the absence of any definite therapy and vaccine at present, the best way to control COVID-19 is prevention.

\section{ESSENTIAL STEPS FOR PREVENTION OF COVID-19 SPREAD}

\subsection{Physical distancing}

The persons infected by the novel coronavirus are the main source of infection. Direct transmission occurs through close physical contact, mainly through respiratory droplets that are released when the infected person coughs, sneezes, or talks. These droplets may also land on nearby surfaces, where the virus may remain viable for a short time period (although the exact duration of viability remains unknown as of now). Although a possibility of aerosol transmission has also been invoked, its significance and impact outside of closed, poorly ventilated settings is yet to be determined.

Table 1: COVID-19 drugs for treatment which are recommended in national health ministry guidelines

\begin{tabular}{|l|l|l|}
\hline \multicolumn{1}{|c|}{ Drug } & \multicolumn{1}{c|}{ Indication } & \multicolumn{1}{c|}{ Mechanism } \\
\hline $\begin{array}{l}\text { 1. Dexamethasone/ } \\
\text { Methylprednisolone }\end{array}$ & $\begin{array}{l}\text { Moderate and severe COVID-19 } \\
\text { (Higher dose in severe COVID-19) }\end{array}$ & $\begin{array}{l}\text { Anti-inflammatory, } \\
\text { immunomodulator }\end{array}$ \\
\hline $\begin{array}{l}\text { 2. Anticoagulant- enoxaparin } \\
\text { immere }\end{array}$ & $\begin{array}{l}\text { Moderate and severe COVID-19 } \\
\text { therapeutic dose in severe COVID- } \\
\text { 19) }\end{array}$ & $\begin{array}{l}\text { Systemic and pulmonary } \\
\text { thromboembolism prevention }\end{array}$ \\
\hline $\begin{array}{l}\text { 3. Remdesivir (Emergency use } \\
\text { authorization) }\end{array}$ & Moderate COVID-19 \\
\hline $\begin{array}{l}\text { 4. Hydroxychloroquine } \\
\text { repurposed/of- label) }\end{array}$ & $\begin{array}{l}\text { Mild COVID-19 with comorbidities } \\
\text { and moderate COVID-19 }\end{array}$ & $\begin{array}{l}\text { Inhibits viral entry, fusion, } \\
\text { and replication }\end{array}$ \\
\hline $\begin{array}{l}\text { 5. Tocilizumab (of-label } \\
\text { recommendation }\end{array}$ & $\begin{array}{l}\text { Moderate disease with progressively } \\
\text { increasing oxygen requirements and in } \\
\text { mechanically ventilated patients not } \\
\text { improving despite use of steroids. }\end{array}$ & $\begin{array}{l}\text { Anti-inflammatory, (IL-6 } \\
\text { inhibitor) }\end{array}$ \\
\hline $\begin{array}{l}\text { 6. Plasma therapy (of-label } \\
\text { recommendation }\end{array}$ & $\begin{array}{l}\text { Moderate disease in who are not } \\
\text { improving (oxygen requirement is } \\
\text { progressively increasing) despite use } \\
\text { of steroids }\end{array}$ & $\begin{array}{l}\text { Immunomodulation (Passive } \\
\text { immunity) }\end{array}$ \\
\hline
\end{tabular}


As such, given that the main route of transmission continues to be droplets, appropriate physical distancing can have a large impact on such spread. In this regard several evidence-based steps are advised and should be routinely followed: use of triple layer surgical mask if working within 1-2 meters of the patient who is in home isolation or when providing care in close contact with a patient with respiratory symptoms (e.g. coughing or sneezing). As per the current evidence, the period of infectivity starts 2-4 days prior to the onset of symptoms (pre-symptomatic phase) and lasts for a variable time period after the onset of symptoms depending on the severity of disease (usually up to 9 days in mild disease). A challenge to control the spread of COVID 19 has been, in large part, attributed to this pre-symptomatic transmission (among other things) which makes it difficult for the contact tracing team to trace the contacts of infected persons (once they are recognised based on symptoms). Thus, it is quint-essential to prevent close physical contact even with apparently healthy people as they may be in a pre-symptomatic phase of their illness (Ish et al., 2020).

Table 2: COVID-19 vaccine which are in various trials in India

\begin{tabular}{|l|l|l|}
\hline \multicolumn{1}{|c|}{ Vaccine } & \multicolumn{1}{|c|}{ Collaborators } & \multicolumn{1}{c|}{ PHASE OF TRIAL } \\
\hline 1. COVAXIN & Bharat Biotech, ICMR, NIV & II (from September 2020) \\
\hline 2. ZyCoV-D & Zydus Cadila & II \\
\hline $\begin{array}{l}\text { 3. ChAdOx1 nCoV-19 (called } \\
\text { Covishield in India) }\end{array}$ & $\begin{array}{l}\text { Oxford, AstraZeneca, Serum } \\
\text { Institute of India }\end{array}$ & III \\
\hline
\end{tabular}

Societal behaviour also has other important far reaching consequences if followed dedicatedly - it has the potential to dramatically reduce Effective reproduction number $(\mathbf{R t}=\mathbf{R 0} \times$ fraction of the population susceptible $\times$ relative societal connectivity), and in turn bring down the usual 'herd immunity threshold'. If, say for example, R0 is 2.5 and social connectivity is $56 \%$ of normal, then realized Rt will be 1.4 , and the herd immunity threshold would be $29 \%$ (compared to $60 \%$ ). To put it into a perspective, a major upward trend in cases is expected if there is even slight relaxation of societal behaviour (which is the likely explanation for the resurgence of cases in some places of India). 


\subsection{Disinfection}

Infection can also occur if a person comes into contact with an infected surface and then touches his or her eyes, nose, or mouth. This is called a fomite transmission. As such, surface cleaning, disinfection and regular hand hygiene by alcohol-based hand rubs is essential to prevent such forms of spread. National Health Ministry guidelines recommend that if equipment needs to be shared among patients even at home isolation, it should be cleaned and disinfected between each patient use. One should avoid contaminating environmental surfaces that are not directly related to patient care (e.g. door handles and light switches).

\subsection{Quarantine and Isolation}

Quarantine and isolation are two sides of the coin; quarantin deals with exposed persons who are not yet diagnosed as infected, and isolation is for patients diagnosed with infection. Isolation can be both institutional or home based and incorporates a lot of instructions- use of masks, hand hygiene, proper disposable of utensils, linen, provision for separate room, telemedicine, supply of essentials,, psychological support and involvement of society for relieving stigma (MoHFW, 2020). Various organizations, based on past epidemic experiences, such as the National Health Ministry, World Health Organization (WHO) and Center for Disease Control (CDC) have laid down the detailed directives for isolation from entry, stay and exit from isolation, with the general acceptance of considering mild/ asymptomatic cases for home and symptomatic cases for institutional isolation. In India, National Health Ministry guidelines recommend downloading the Aarogya Setu mobile app for monitoring which includes symptoms and time frame-based exit policy (MoHFW, 2020). When followed appropriately, isolation has the potential to work in unison with other measures in breaking the transmission chain (Figure 1A and 1B).

Institutional isolation has been given preference over home isolation in populationbased simulation models, as the former showed better results in terms of delay in time to achieve epidemic peak, number of cases at peak and an overall reduction of cases by $57 \%$ as compared to $20 \%$ in home isolation during the pandemic. However, the availability and burden on health resources must also be taken into account in countries 
like India and a judicious severity-based strategy is the best bet (Niu et al., 2020). All home isolated patients should be under regular monitoring through the district surveillance officer, have a $24 \times 7$ caregiver and should be in contact with a doctor and referral facility nearby.
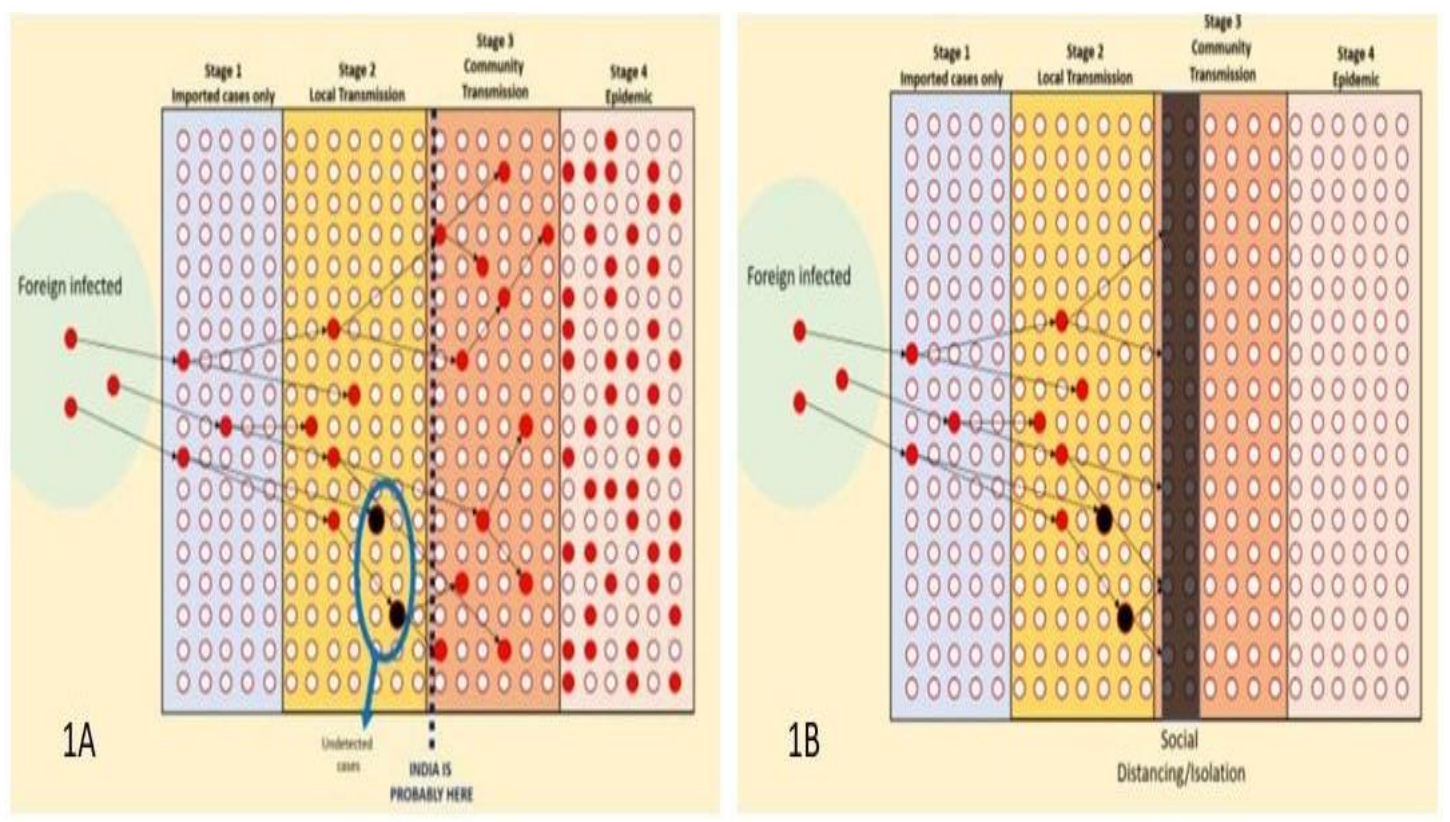

Figure 1: The potential of exponential transmission in the community $(1 \mathrm{~A})$ which can effectively be blocked by isolation (1B)

\subsection{Instructions for caregiver and patients in Home-isolation}

The caregiver should wear a triple layer medical mask appropriately when in the same room with the ill person. The front portion of the mask should not be touched or handled during use. If the mask gets wet or dirty with secretions, it must be changed immediately. The mask should be discarded after use and hand hygiene should be performed after disposal of the mask. He/she should avoid touching own face, nose or mouth. Hand hygiene must be ensured following contact with an ill person or his immediate environment. Hand hygiene should also be practiced before and after preparing food, before eating, after using the toilet, and whenever hands look dirty. Use soap and water for hand washing at least for 40 seconds. Alcohol-based hand rub can be used, if hands are not visibly soiled. After using soap and water, use of disposable paper towels to dry hands is advisable. If not available, use dedicated clean cloth towels and replace them when they become wet. Avoid direct contact with body fluids of the 
patient, particularly oral or respiratory secretions. Use disposable gloves while handling the patient. Perform hand hygiene before and after removing gloves. Avoid exposure to potentially contaminated items in his immediate environment (e.g. avoid sharing cigarettes, eating utensils, dishes, drinks, used towels or bed linen). Food must be provided to the patient in his room. Utensils and dishes used by the patient should be cleaned with soap/detergent and water wearing gloves. The utensils and dishes may be reused. The car giver has to make sure that the patient follows the prescribed treatment and he shall self-monitor his health with daily temperature monitoring and should be advised to report promptly if they develop any symptom suggestive of COVID-19 (fever/cough/difficulty in breathing).

The patient in home-isolation should at all times use triple layer medical mask. He should discard the mask after 8 hours of use or earlier if it becomes wet or visibly soiled. Mask should be discarded only after disinfecting it with $1 \%$ Sodium Hypo-chlorite. The identified room should be away from other people in home, especially elderlies and those with comorbid conditions like hypertension, cardiovascular disease, renal disease etc. Hands must be washed often with soap and water for at least 40 seconds or cleaned with alcohol-based sanitizer. Cleaning surfaces in the room that are touched often (tabletops, door knobs, handles, etc) with $1 \%$ hypochlorite solution must be ensured. The patient must take rest and drink lot of fluids to maintain adequate hydration, follow the physician's instructions and medication advice, self-monitor his/her health with daily temperature monitoring and report promptly if he/she develops any deterioration of symptoms (MoHFW, 2020). All these steps taken by caregiver and patient help prevent spread of infection to other household members and thereby to the community.

\subsection{Public education}

Hospitals and the national authorities have an important role in spreading public education regarding the correct and effective preventive measures. They should display posters, advertisements and videos on cough etiquette and hand hygiene. The general public must be educated on the following - Cough on the sleeve rather than the hand, touch lift and door knobs with elbows, greet people without physical handshake or hugs, consult a doctor if there are any symptoms and apply home quarantine or isolation 
wherever appropriate. The public must remember to follow guidelines issued by authorities like Ministry of Health, ICMR, AIIMS and not rely on fake WhatsApp and media circulations; most of which are unscientific and myths.

\subsection{Comorbidities}

The majority of COVID-19 infections in India have been mild (Gupta et al., 2020). There has been an increased morbidity and mortality in patients with comorbidities like - diabetes mellitus, hypertension, chronic heart, lung kidney or liver disease (Shalimar et al., 2020). Thus, all such patients should maintain constant vigil on their treatment of underlying illness, exposure to COVID-19 patients and prevention. Such patients should not stop their usual medications and continue regular follow-up with their respective speciality doctor. Myths regarding safety of various drugs in COVID-19 are rampant and should not be viewed seriously.

\subsection{Drugs}

Hydroxychloroquine has been suggested by national guidelines for high risk contacts as a prophylaxis for prevention of COVID-19. As it has not been conclusively proven to be protective (Rathi et al., 2020) and only has a limited role in treatment (Elavarasi et al., 2020), intake of Hydroxychloroquine should not give a false sense of security and other preventive measures mentioned above must be prioritized.

\subsection{Telemedicine}

In the modern age of technology, telemedicine can help in public education, dispelling myths, counselling, patient care and treatment. It can help all patients or suspects or symptomatic people consult the appropriate authorities (Malhotra et al., 2020).

\section{CONCLUSION}

Thus, it is the responsibility of each one of us to help break the chain of transmission of this highly contagious virus. The ultimate weapons remain physical distancing, masks, quarantine, isolation and mass education which are the key to break the rise and spread of this pandemic illness.

\section{REFERENCES}


Gupta, N., Agrawal, S., Ish, P., Mishra, S., Gaind, R., Usha, G., Singh, B. \& Sen, M.K. (2020). Clinical and epidemiologic profile of the initial COVID-19 patients at a tertiary care centre in India. Monaldi Archives for Chest Disease, 90(1). https://doi.org/10.4081/monaldi.2020.1294

Corona Meter (2020). https://coronameter.co/ Last accessed 13 September 2020

RECOVERY Collaborative Group (2020). Dexamethasone in Hospitalized Patients with Covid-19 - Preliminary Report. The New England Journal of Medicine, DOI: $10.1056 /$ NEJMoa2021436

Ish, P., Agrawal, S., Goel, A.D. \& Gupta, N. (2020). Contact tracing: Unearthing key epidemiological features of COVID-19. SAGE Open Medical Case Reports, https://doi.org/10.1177\%2F2050313X20933483

MoHFW (Ministry of Home and Family Welfare) (2020). https://www. mohfw.gov.in/pdf/RevisedguidelinesforHomeIsolationofverymildpresymptom aticCOVID19cases10May2020.pdf/ (Last accessed 13 September 2020)

Niu Y, Xu F. (2020). Deciphering the power of isolation in controlling COVID-19 outbreaks. The Lancet Global Health, 8(4), e452-e453. https://doi.org/10.1016/S2214-109X(20)30085-1

Shalimar, Elhence, A., Vaishnav, M., Kumar, R., Pathak, P.,......Garg, P. (2020). Poor outcomes in patients with cirrhosis and Corona Virus Disease-19 . Indian Journal of Gastroenterology, 39, 285-291. https://doi.org/10.1007/s12664-02001074-3

Rathi, S., Ish, P., Kalantri, A. \& Kalantri, S. (2020). Hydroxychloroquine prophylaxis for COVID-19 contacts in India. The Lancet Infectious Diseases, 20(10), P1118-P1119. https://doi.org/10.1016/S1473-3099(20)30313-3

Elavarasi, A., Prasad, M., Seth, T., Sahoo, R.K., Madan, K.,.......Garg, P. (2020). Chloroquine and Hydroxychloroquine for the Treatment of COVID-19: a Systematic Review and Meta-analysis. Journal of General Internal Medicine, https://doi.org/10.1007/s11606-020-06146-w 
Malhotra, N., Gupta, N. \& Ish, P. (2020). Coronavirus - preventing an occupational hazard among doctors. Advances in Respiratory Medicine, 88(2):166-168. doi:10.5603/ARM.a2020.0096

How to cite this article: Ish, P. \& Nischal, N. (2020). COVID-19 in India; A brief review of preventive measures and the path ahead. Vantage: Journal of Thematic Analysis, 1(2): 12-20

DOI: https://10.52253/vjta.2020.v01i02.03

(C) The Author(s) 2020.

This work is licensed under a Creative Commons Attribution 4.0 International License which permits its use, distribution and reproduction in any medium, provided the original work is cited. 